\title{
Regional Econometric Forecasting: Linkages to Labor Supply
}

\author{
Neil O. Alper*
}

\section{A Statement of the Problem}

Regional econometric modeling has come a long way in the last decade. According to Professor J. W. Milliman, "Econometric techniques and regional economic theory have come of age." It is true that in forecasting demand characteristics of a region's economy, regional economists have made considerable advances. The modeling of regional supply characteristics has not really advanced from the early work in regional econometric modeling, but is of growing concern to modelers at all levels. ${ }^{2}$

Regional labor markets provide an opportunity to examine an important supply characteristic of a regional economy. In most regional econometric models the labor market is primarily demand-oriented. ${ }^{3} \mathrm{It}$ generally includes an employment sector where the employment relationships take the form of inverse production functions. A behavioral relationship for the regional unemployment rate is often a component of this sector, enabling the calculation, through an identity, of a regional labor force and the number of people unemployed. ${ }^{4}$ Direct consideration of supply characteristics of the labor market is either forgotten or included as an afterthought.

Including the supply portion of the labor market ${ }^{5}$ as a part of a regional econometric model provides a tool for policy analysis and development. Planners involved in the development of programs to provide employment and training services to the region are likely to find this information very useful. Coordinated with a more detailed description of employment demand a detailed projection of the available labor force by occupation has the potential for minimizing the impact of labor market bottlenecks on the region's economy. Planners involved in developing policies to aid in regional development would also be interested in labor supply forecasts. This information can be used in developing a program designed to attract, new businesses and industry to the region. ${ }^{6}$

The methods that other researchers have utilized in attempting to develop forecasts of labor supply are reviewed first. A detailed description of the components of the labor supply model as it has been incorporated

\footnotetext{
*Assistant Professor, Department of Economics, Northeastern University. I would like to thank Henry W. Herzog, $\mathrm{Jr}$. and two anonymous reviewers for their helpful comments and suggestions. I would also like to thank Yu Hsing and James Thompson for their assistance in providing the computation, data collection and empirical analysis. This research was done while at the Center for Business and Economic Research, The University of Tennessee.
} 
into a regional econometric model of Tennessee follows. Next is an example of its application and use in developing regional growth strategies and employment and training policies.

\section{METHODS OF FORECASTING THE SUPPLY OF LABOR}

Supply forecasting methodologies are primarily limited to two types-a skill inventory methodology and an economic-demographic modeling methodology. The skill inventory methodology requires identification of the labor force at a given point, then adjustment over time for separations from the labor force and new entrants to the labor force. ${ }^{7}$ Separations may be due to retirement, death or individual choice (i.e., childbirth, schooling, out-migration, etc.). New entrants to the labor force may come from people returning after temporary withdrawal from the labor force, inmigrants, and graduates of or dropouts from educational programs. This methodology is costly in terms of data collection needs, especially the costs of inventorying the new entrants. It is also a static methodology that is not well-suited to simulating the impact of changes in the regional or national economic environment on supply conditions in the labor market.

An alternative to the skill inventory methodology is the development of a model that combines economic and demographic modeling methodologies. The component parts needed to forecast the labor force are forecasts of the population and forecasts of labor force participation rates.

Population forecasting methodologies can be grouped into two types. Mathematical population forecasting methodologies generally represent the population growth process as an explicit functional form with the primary concern being to forecast total population without considering the causes of population changes or population characteristics. ${ }^{8}$ Component forecasting methodologies disaggregate population change into its three primary components-fertility, mortality and migration. This allows for the integration of multiple forecasting methods for the different component parts as well as for disaggregation of the population cohorts. Considerable research has been done by economists to develop theories and models of fertility ${ }^{9}$ and migration, ${ }^{10}$ but little has been done to incorporate them into a population projection system. ${ }^{11}$ Even less has been done to coordinate such a system with a regional econometric model which could provide the researcher with forecasting and simulation potential not previously available. ${ }^{12}$

Economic research into labor force participation rates and the forecasting of these rates has a long history, ${ }^{13}$ especially at the national level. ${ }^{14}$ Three basic research methodologies have been followed in examining aggregate labor force behavior. Time-series analysis is primarily used when examining the determinants of changes in labor force participation over time, and this method is well suited for forecasting purposes. In dealing with a regional labor market, time-series analysis has very little applicability due to the lack of time-series data ${ }^{15}$ Cross-section analysis is primarily used to examine the determinants of labor force participation at 
a given point in time,${ }^{16}$ but it has limited potential in producing forecasts. The third methodology, pooling cross-sectional data over time, is gaining in popularity due to the availability of data. Also, it permits the modeling of aggregate, regional labor force behavior for almost any cohort classification system, while its forecasting properties are better than a simple crosssection analysis. ${ }^{17}$

\section{THE MODELING METHODOLOGY}

The modeling methodology used to link a labor supply model to the regional macroeconometric model for Tennessee requires the development of a population model and a labor force model. The structure of the labor supply model and the linkages between it and the Tennessee Econometric Model $^{18}$ (TEM) are through the variables forecast by TEM. How the structure is affected as well as what the linkages are will be described in detail below.

\section{The Population Model}

The population forecasting component of the model integrates both economic and demographic methodologies through the cohortcomponent method of population forecasting. This methodology takes a base year population which is disaggregated into age-sex cohorts and subjects it to the two components of population changes-natural change and migration. The model is designed to forecast population for 18 fiveyear age cohorts for both sexes using the 1970 Census as the base year.

Natural Change. Natural change in a population is defined as births and deaths. The number of births are projected through a general fertility rate applied to the female population at risk to childbirth (all women 15 to 44 years old). An adjusted national fertility rate is calculated based on a forecast national fertility rate that is designed to reach the replacement level of 2.1 children per woman early in the next century. ${ }^{19}$ The sex distribution of births is obtained by applying a fixed ratio based on the historical relationship of the number of total births.

The number of deaths are forecast from age-sex specific survival ates. These rates are state-adjusted, nationally projected survival rates. ${ }^{20}$ The adjustments are based on the historical relationship between the state and national rates.

Migration. In the cohort-component methodology of population forecasting, it is the net number of migrants by age and sex that is needed. (Net migrants $=$ in-migrants minus out-migrants.) In order to obtain a forecast of net migration it is necessary to forecast the gross flows of in-migrants and out-migrants separately. Economic theory and current empirical research indicate that direct estimation of a net-migration relationship is inappropriate. ${ }^{21}$ For this reason, separate migration functions are estimated for the gross flows.

The functional form of the migration relationships incorporates economic factors as well as demographic and noneconomic characteristics of 
the origin and destination regions. The economic factors are the mechanism that links the population component with the state macroeconomic model. The functional forms of these relationships are:

and

$$
\operatorname{RIMIG}_{t, t+5}^{\mathrm{ij}}=\mathrm{f}_{1}(\mathrm{ECON}, \mathrm{DEMO}, \mathrm{CHAR}, \mathrm{PMIG})
$$

where

$$
\operatorname{ROMIG}^{\mathrm{ij}}{ }_{t, t+5}=\mathrm{f}_{2}(\mathrm{ECON}, \mathrm{DEMO}, \mathrm{CHAR}, \mathrm{PMIG})
$$

RIMIG ${ }_{t, t+5}^{\mathrm{ij}}\left(\operatorname{ROMIG}_{\mathrm{t}, t+5}^{\mathrm{ij}}\right)=$ the rate of in- (out-) migration for the $\mathrm{ij}^{\text {th }}$ age-sex cohort over the five-year period to $\mathrm{t}+5$;

$\mathrm{ECON}=$ economic factors that are likely to influence migration, such as regional economic growth and labor market conditions;

DEMO = demographic factors, such as: the migration patterns of parents and spouses; and past migration of friends and relatives;

$\mathrm{CHAR}=$ noneconomic destination characteristics for the in-migrants and origin characteristics for the out-migrants, such as average annual temperature and population density;

PMIG = past propensities to migrate.

The forecasts for the migration rates are used in conjunction with the base population to obtain the gross flows of in-migrants $\left(\mathrm{INMIG}^{\mathrm{ij}} \mathrm{t}, \mathrm{t}+5=\right.$ $\mathrm{RIMIG}_{\mathrm{t}, \mathrm{t}+5}^{\mathrm{ij}} \times \mathrm{POP}_{\mathrm{t}}^{\mathrm{ij}}$ ) and out-migrants (OUTMIG ${ }_{t, t+5}^{\mathrm{ij}}=\mathrm{ROMIG}_{\mathrm{t}, t+5} \mathrm{X}$ $\left.\mathrm{POP}^{\mathrm{ij}}{ }_{\mathrm{t}}\right)$ and the number of net migrants:

$$
\mathrm{NMIG}_{\mathrm{t}, \mathrm{t}+5}^{\mathrm{ij}}=\mathrm{INMIG}_{\mathrm{t}, \mathrm{t}+5}^{\mathrm{ij}}-\mathrm{OUTMIG}_{\mathrm{t}, \mathrm{t}+5}^{\mathrm{ij}} \text {. }
$$

The basis for this model of interstate migration stems from considerable theoretical and empirical literature in this field. Previous studies have shown that there exist economic and noneconomic factors in a region that act as either attractive or repulsive forces. Economic growth and labor market conditions, factors which are likely to be highly correlated, are examples of these forces. Miller has shown that economic growth, as measured by the rate of growth in employment, is a primary determinant of the rate of out-migration. ${ }^{22}$ Both Courchene and Lowry found evidence that migration is related to the unemployment rate; the former found the unemployment rate directly related to out-migration and the latter found it negatively related to in-migration. ${ }^{23}$

The demographic factors primarily influence the availability and costs of information important in making the migration decision as well as the psychic and out-of-pocket costs incurred when migrating. The presence of family and friends at a destination due to past migration or other factors decreases the cost of obtaining information about the area and increases the quantity, and possibly quality, of the information. Nelson, Greenwood, Fabricant and others have found that the presence of friends or relatives at the destination and the past migration of friends or relatives have an important influence on current migration behavior. ${ }^{24}$ Other researchers have found that past migration on the part of individuals increases the 
probability of their migrating again in the future relative to those people who have never migrated. ${ }^{25}$

A number of non-economic locational characteristics have been found to be important in attracting migrants. More temparate climates have been found to have an attractive force relative to less temparate climates. ${ }^{26}$ Less densely populated areas are found to be attractive and the more densely repulsive as people attempt to escape rising crime problems in urban and more densely populated areas. Another proxy used to measure the attractiveness of an area is its education composition. An area characterized by a well educated population is viewed as being more attractive than an area not as well educated. ${ }^{27}$

Data limitations do not permit the use of time-series analysis for estimating the migration relationships since the only source of age-sex specific gross migrant flows of regional population migration, rather than labor or work force migration, ${ }^{28}$ is the national decennial census. The census provides gross flows for a five-year period (i.e., the 1970 Census provides inand out-migration flow data for the period 1965 to 1970). Five-year migration rates are developed from this data. ${ }^{29}$ Estimation of the above migration relationships is accomplished through pooling cross sections from the two most recent decennial censuses. ${ }^{30}$ This changes the migration equations to:

and

$$
\text { RIMIG }_{\mathrm{t}, \mathrm{t}+5}^{\mathrm{ij}}=\mathrm{f}_{3}(\text { ECON, DEMO, CHAR, PMIG, POOL) }
$$

$$
\text { ROMIG }{ }_{t, t+5}^{\mathrm{ij}}=\mathrm{f}_{4}(\text { ECON, DEMO, CHAR, PMIG, POOL) }
$$

where

$$
\begin{aligned}
\text { POOL }= & \text { a shift variable that takes the value of zero for } 1960 \\
& \text { and one for } 1970 .
\end{aligned}
$$

The cross section is composed of 12 southeastern states, ${ }^{31}$ including Tennessee. The estimated migration relationships are then used to forecast five-year gross migration rates which are based on forecasts for the exogenous variables, some of which come from the forecasts of the macroeconomic model.

In terms of explained variation (adjusted $\mathrm{R}^{2}$ ), the in-migration equations perform better than the out-migration equations, with the $\overline{\mathrm{R}}^{2}$ ranging from .82 to .99 for the former and .48 to .96 for the latter. In general, migration rates for the youngest age groups, 5 to 9 and 10 to 14 , are found to be related to migration rates of females of the expected ages of their parents (i.e., females 20 to 24,25 to 34,35 to 44 and 45 to 54). For the remaining age groups in- and out-migration rates are generally found to be related to: the relative rate of economic growth, which is derived from the macroeconomic model, with in-migration positively related to the rate of economic growth and out-migration negatively related; past migration of the age-cohort, with a positive relationship between past migration into (out of) a region and current migration out of (into) a region; and several non-economic characteristics of the origin (destination), including degree of urbanization, average temperature and racial composition of the reg- 
ion. These results generally followed theoretical expectations as well as earlier empirical results as described above. The strength of the economic variables in explaining out-migration as well as in-migration is somewhat surprising given other researchers failures in this area. Estimated in- and

TABLE 1

SELECTED MIGRATION EQUATIONS

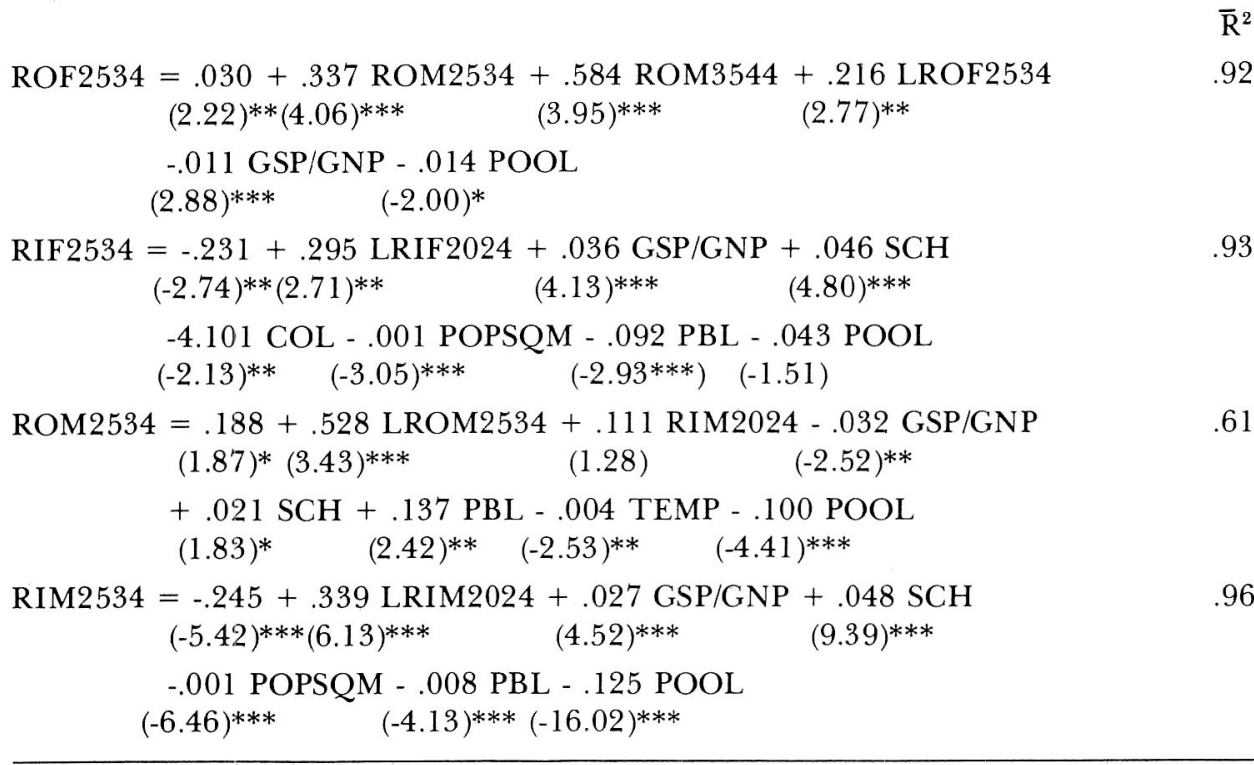

ROFkl (ROM): $\quad$ Rate of female (male) out-migration for the cohort between ages $\mathrm{k}$ and $\mathrm{l}$.

RIFkl (RIM): $\quad$ Rate of female (male) in-migration for the cohort between ages $\mathrm{k}$ and $\mathrm{l}$.

LROFkl (LROM): Lagged rate of female (male) out-migration for the cohort between ages $\mathrm{k}$ and $\mathrm{l}$.

LRIFkl (LRIM): Lagged rate of female (male) in-migration between ages $\mathrm{k}$ and $\mathrm{l}$.

COL: $\quad$ Percent of college students out of total population.

GSP/GNP: $\quad$ Ratio of percent change of gross state product and percent change of gross national product.

PBL: $\quad$ Percent of blacks out of total population.

SCH: Median number of school years completed.

POPSQM: $\quad$ Population per square mile.

TEMP: Average temperature.

POOL: $\quad$ Dummy variable $(1960=0$ and $1970=1)$.

*: $\quad$ T-test significant at .10 .

**: $\quad$ T-test significant at .05 .

***: $\quad$ T-test significant at .01 . 
out-migration functions for the male and female 25 to 34 age cohort are presented in Table 1. They are illustrative of the estimated equations for the remaining age-sex cohorts. ${ }^{32}$

Computation. The order in which population forecasts derived from the cohort-component method are computed will influence the final outcome. Whether the base population is first survived and then subject to migration or the reverse will influence the final outcome for each cohort. For the 0 to 4 cohort, when the fertility rate is applied, is especially important since the migration rates and survival rates differ for each of the female cohorts at risk to childbirth. Therefore, an averaging procedure is followed to minimize the potential error. ${ }^{33}$ The general procedure requires four steps: (1) age the base year population (e.g., all those in the 0 to 4 cohort in year $t$ are in the 5 to 9 cohort in year $\mathrm{t}+5$ ); (2) survive the resulting cohorts through the projected survival rates; (3) migrate the cohorts by applying the projected migration rates to year t population and then adding in the net in-migrants; and (4) obtain the births by applying the projected fiveyear general fertility rate to the female population at risk to childbirth. After adjusting for both the sex distribution and for deaths, this group becomes the 0 to 4 year-old cohort. The averaging process requires applying the procedure as specified, then recomputing it while reversing the order of the survival and migration calculations (steps 2 and 3 ) and taking the average of these forecasts.

The above procedure produces five-year population forecasts. Annual forecasts are obtained through an interpolation procedure. Adjustments are also made to U.S. Bureau of the Census estimates of the state's total population when necessary.

\section{The Labor Force Model}

The labor force component of the model has its foundation in economic theory and prior empirical research, but it is also subject to the restrictions involved in integrating it into a regional econometric forecasting model. The linkages of the labor supply component to the macroeconomic model come primarily from forecasting labor force behavior, but also indirectly from the population forecasts described above. Together, labor force participation rate forecasts and population forecasts are utilized to produce labor supply forecasts. Then the age-sex specific labor force forecasts are used to obtain labor force forecasts by occupation.

Labor Force Participation. The labor force participation component of the model is used to forecast the labor force participation rates separately for males and females in each of six age cohorts ( 16 to 19, 20 to 24,25 to 34,35 to 44,45 to 64 and 65 and older). The general structure of the relationships is such that labor force participation rates are determined by conditions in the labor market (LMC), economic incentive to enter the labor market (INC) and characteristics of the population (CHAR). Conditions in the labor market related to such factors as the region's unemployment rate, the size of the labor market and the rate of economic growth. As labor market conditions tighten, i.e. as the unemployment rate gets lower and 
the rate of real economic growth accelerates, it is expected that the labor force participation rates of women, especially older married women, and young men will increase since they comprise the largest portion of the secondary labor force and are more sensitive to changes in economic activity than prime age men. Incentives to enter the labor market, i.e. those things that increase the size of the substitution effect, are related to factors such as potential earnings or income received, while disincentives which may inhibit participation, i.e. those things that increase the income effect, are such factors as earnings of other family members, especially spouses, and availability of other sources of income (i.e., welfare, unemployment insurance and retirement benefits). The characteristics of the population that influence labor force behavior are education and the racial composition of the labor force. Labor force participation increases with education for all races and both sexes while the labor force participation of black females is generally higher than for black males.

The desired methodology for estimating the twelve labor force participation relationships is time-series analysis. Again, there is no time-series data on labor force behavior at a state level that would provide the necessary age-sex detail. ${ }^{34}$ Therefore, the labor force participation rate equations estimated were:

$$
\text { LFPR }_{i}^{\text {ij }}=g(\text { LMC, INC, CHAR, POOL }),
$$

where POOL is a shift variable for the two cross sections utilized, ij is the age-sex cohort and t is time. The pooled cross sections are from the two most recent censuses for the same southeastern states. These restrictions are important to control for the socio-cultural environment of the region that is likely to influence labor force behavior, especially female behavior.

Using this methodology the amount of explained variance (adjusted $\mathrm{R}^{2}$ ) ranges from .55 to .97 for the female equations and from .53 to .89 for the male equations. Average annual wage by industry (in 1972 dollars) and the unemployment rate provide the connection with the macroeconomic model. For most of the female equations, average real wages in the female-dominated industries (such as service and wholesale and retail trade) are positively related to the labor force participation, while average real wages in the male-dominated industries (such as manufacturing and construction) are negatively related to participation rates. The maledominated industry wage variables are proxies for other family income and, therefore, the negative relationship is expected. The negative relationship between the unemployment rate variables and females participation rates is expected since females comprise much of the secondary labor force, as discussed above. For three of the male equations-men 16 to 19 , 45 to 64 and 65 and older - the pooling dummy is highly significant and negative, indicating that something other than a change in the economic environment has influenced its behavior. This result is not unexpected for the two older age cohorts. In general all the results were expected based on theory and other empirical studies. There are exceptions with regard to 
some of the wage variables. This may be due to an identification problem caused by using the wage rate to explain labor force participation. This problem cannot be easily resolved given the data limitations. Estimates of the male and female labor force participation rate equations for the 25 to 34 age cohort are found in Table 2 . They are illustrative of the estimated equations for the other age-sex cohorts. ${ }^{35}$

Labor Force. The projections of the age-sex specific labor force participation rates, combined with projections of the age-sex cohorts from the population component of the model ${ }^{36}$ provide forecasts of total labor force and detailed forecasts by age and sex. In making location decisions businesses are concerned with the characteristics of the labor force including its size; the age and sex composition as well as its occupational structure.

An occupational distribution of the experienced labor force is obtained by combining the age-sex specific projections of the labor force with two matrices, one for each sex, that distribute the labor force cohort projections by occupation. The matrices are derived from the 1970 Census of

TABLE 2

SELECTED LABOR FORCE PARTICIPATION RATE EQUATIONS

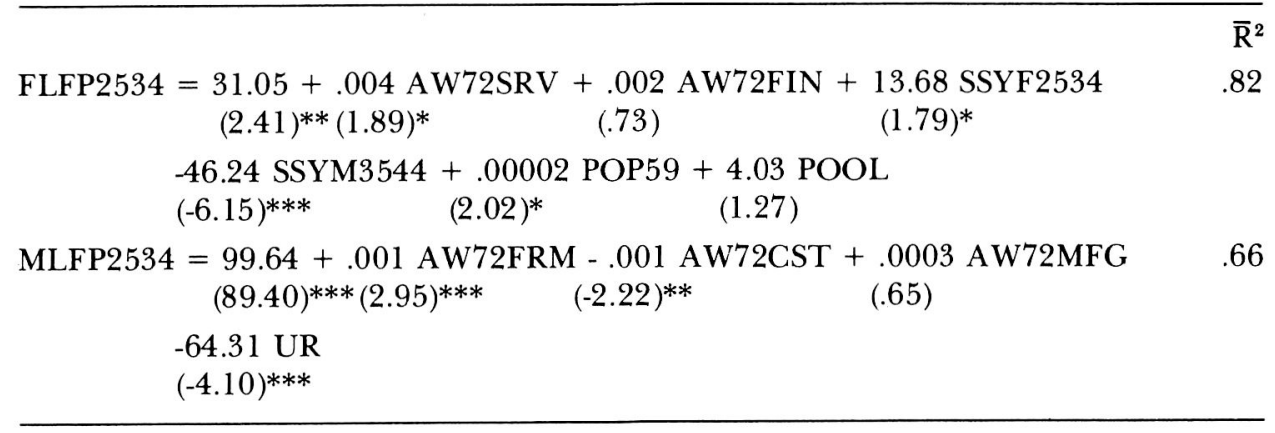

FLFP $_{\mathrm{kl}}(\mathrm{MLFP}): \quad$ Female (male) labor force participation rate for the cohort between ages $\mathrm{k}$ and $\mathrm{l}$.

AW72MFG: Average annual wage for manufacturing in 1972 dollars.

AW72FRM:

AW72CST:

AW72SRV:

AW72FIN:

UR:

POP59:

SSYM3544:

Average annual wage for agriculture in 1972 dollars.

Average annual wage for construction in 1972 dollars.

Average annual wage for services in 1972 dollars.

Average annual wage for finance in 1972 dollars.

Unemployment rate.

Population aged 5 to 9 .

Relative median income for males aged 35 to 44 between state and Southeast.

SSYF2534: $\quad$ Relative median income for females aged 25 to 34 between state and Southeast.

$\begin{array}{ll}\text { POOL: } & \text { Dummy variable }(1960=0 ; 1970=1) . \\ *: & \text { T-test significant at } .10 . \\ * *: & \text { T-test significant at } .05 . \\ * * *: & \text { T-test significant at } .01 .\end{array}$


Population which provides a detailed occupational distribution of the labor force. ${ }^{37}$ They are developed by combining information on the agesex distribution of individuals' occupations for the employed and for the last occupation for the experienced unemployed. ${ }^{38}$ Adjustments are made to obtain conformity between the male and female occupational categories.

\section{Application of the Model and Its Use in Policy Development}

Using the labor supply model developed in this article as part of a comprehensive macroeconomic forecasting system to analyze the impact of national economic policies provides a wealth of information concerning economic and demographic conditions not previously available. Based on a set of forecasts for the nation's economy, the labor supply model produces annual forecasts for Tennessee's population and labor supply by occupation. This information is certainly useful in designing employment and training programs as well as in assisting in attracting business and industry for continued regional growth and development.

As part of the continued development of the "Sun Belt" region of the country, Tennessee's population is forecast to continue to grow over the period 1979 to 1986 . As indicated by the forecasts for Tennessee's population, total population is likely to be almost 4.7 million by 1986 , an increase of almost 6 percent over the period. This compares to a growth of almost 9 percent over the 1971 to 1978 period. The slow down in population growth is primarily due to the general slow down in economic growth in the nation and the state forecast for the early 1980s. Much of the forecasted increase is due to increases in the number of in-migrants relative to the number out-migrants over the period. Tennessee's population will be aging, with the population under 20 years of age comprising a smaller percentage of the population and the population between the ages of 25 to 34 increasing its proportion of Tennessee's population.

A growth rate of just over 10 percent for the 1979 to 1986 period is indicated by Tennessee's labor force forecasts. The female component of the labor force is expected to grow more rapidly than the male component, almost 12 percent and just over 9 percent, respectively. The reasons for the differentials in growth are projected increases in labor force participation rates for almost all the female cohorts and relatively stable participation rates for the male cohorts. Other factors influencing the growth in the labor force are the growth and aging of the population, with the primary labor force age cohorts showing considerable relative gains.

The occupational composition of the group of qualified people is significantly influenced by the forecast changes in the size and age-sex composition of the labor force. Indicated by the forecasts in Table 3 is that the number of people qualified for professional and technical occupations will increase at the fastest rate, followed by the number of people qualified for managers and administrators occupations, crafts occupations, transportation equipment operatives occupations, operative occupations (excluding transportation operatives), clerical occupations, sales occupations, service 
TABLE 3

TENNESSEE LABOR FORCE BY OCCUPATION

1978-1986

(Thousands of Persons)

\begin{tabular}{|c|c|c|c|c|c|c|c|c|c|}
\hline Occupation & 1978 & 1979 & 1980 & 1981 & 1982 & 1983 & 1984 & 1985 & 1986 \\
\hline Professional, Technical, and Kindred & 231.5 & 236.6 & 241.6 & 244.4 & 248.1 & 252.3 & 256.9 & 261.6 & 266.9 \\
\hline Percent Change & 2.2 & 2.2 & 2.1 & 1.2 & 1.5 & 1.7 & 1.9 & 1.8 & 2.0 \\
\hline Managers and Administrators (Except Farm) & 132.7 & 135.7 & 138.0 & 139.2 & 141.3 & 143.9 & 146.3 & 149.2 & 152.1 \\
\hline Percent Change & 2.0 & 2.2 & 1.6 & 0.9 & 1.5 & 1.8 & 1.7 & 2.0 & 1.9 \\
\hline Sales Workers & 123.4 & 125.6 & 127.3 & 128.4 & 129.8 & 131.5 & 133.1 & 135.1 & 137.3 \\
\hline Percent Change & 2.1 & 1.8 & 1.3 & 0.9 & 1.1 & 1.3 & 1.2 & 1.5 & 1.6 \\
\hline Clerical and Kindred & 300.2 & 305.2 & 310.4 & 313.3 & 316.5 & 320.3 & 325.1 & 329.4 & 334.9 \\
\hline Percent Change & 1.8 & 1.6 & 1.7 & 0.9 & 1.0 & 1.2 & 1.5 & 1.3 & 1.7 \\
\hline Craftsmen and Kindred & 263.3 & 269.5 & 274.7 & 277.1 & 280.7 & 285.5 & 289.9 & 295.3 & 300.1 \\
\hline Percent Change & 1.9 & 2.3 & 1.9 & 0.9 & 1.3 & 1.7 & 1.5 & 1.9 & 1.6 \\
\hline Operatives (Except Transportation) & 405.9 & 413.2 & 420.7 & 424.7 & 430.0 & 436.2 & 442.9 & 450.1 & 458.1 \\
\hline Percent Change & 2.0 & 1.7 & 1.8 & 1.0 & 1.2 & 1.4 & 1.1 & 1.6 & 1.8 \\
\hline Transportation Equipment Operatives & 83.6 & 85.5 & 87.2 & 88.0 & 89.1 & 90.6 & 91.9 & 93.7 & 95.1 \\
\hline Percent Change & 1.2 & 2.3 & 2.0 & 0.9 & 1.3 & 1.7 & 1.4 & 2.0 & 1.5 \\
\hline Laborers (Except Farm) & 95.3 & 96.6 & 97.5 & 97.8 & 98.2 & 98.8 & 99.1 & 99.8 & 100.5 \\
\hline Percent Change & 1.8 & 1.4 & 0.9 & 0.3 & 0.4 & 0.6 & -0.3 & 0.7 & 0.7 \\
\hline Farmers and Farm Managers & 39.2 & 40.0 & 40.1 & 40.3 & 40.8 & 41.2 & 41.6 & 42.3 & 42.7 \\
\hline Percent Change & 2.3 & 2.0 & 0.3 & 0.9 & 1.2 & 1.0 & 1.0 & 1.7 & 0.9 \\
\hline Farmer Laborers and Farm Foremen & 25.7 & 26.1 & 26.3 & 26.5 & 26.6 & 26.9 & 27.0 & 27.2 & 27.5 \\
\hline Percent Change & 2.0 & 1.6 & 0.8 & 0.8 & 0.4 & 1.1 & 0.4 & 0.7 & 1.1 \\
\hline Service Workers & 242.0 & 245.3 & 247.9 & 249.8 & 252.6 & 255.5 & 258.8 & 262.1 & 266.9 \\
\hline Percent Change & 2.1 & 1.4 & 1.1 & 0.8 & 1.1 & 1.1 & 1.3 & 1.3 & 1.8 \\
\hline Total & $1,942.8$ & $1,979.4$ & $2,011.8$ & $2,029.6$ & $2,053.6$ & $2,082.3$ & $2,112.5$ & $2,145.7$ & $2,182.1$ \\
\hline Percent Change & 2.0 & 1.9 & 1.6 & 0.9 & 1.2 & 1.4 & 1.5 & 1.6 & 1.7 \\
\hline
\end{tabular}


occupations, farmers and farm managers occupations, farm laborers and other laborers. ${ }^{39}$ There is considerable variation in projected occupational changes with relatively little growth in those occupations which are historically dominated by the younger labor force cohorts, such as garage workers and gas station attendants. There is relatively rapid growth in those occupations historically dominated by the female cohorts, such as dressmakers and seamstresses.

In conjunction with forecasts of labor demand by occupation ${ }^{40}$ these forecasts of labor supply can be utilized to make recommendations concerning the development of employment and training programs to better serve the needs of Tennessee and to eliminate potential labor market bottlenecks. A more detailed analysis of the market imbalances would need to be undertaken to provide the information for the development of the most effective employment training programs. By itself, this information can be used to attract industry and business to Tennessee. This information can be used by firms to make their location decision based on the information on the characteristics of labor force that will exist in the state in the early to mid-1980s.

\section{CONCLUSION}

This article has described in detail the methodology utilized to extend a regional econometric forecasting model into areas not previously included in macroeconomic forecasting models. This has been accomplished by integrating economic and demographic theory with available methodologies within the restrictions imposed by a regional econometric model and regional data limitations. Data from the model is used to analyze the impact of changes in the economic environment and government policy on additional aspects of the region's economy than those that are consistent with the more traditional measures of regional economic growth and well-being. In particular, previously unavailable information that would be useful to governments in designing employment and training programs and regional economic development strategies is made available. The model can readily be extended to encompass questions relating to the age structure of the population (such as forecasting Medicare-Medicaid expenditures in the region). The methodology is not uniquely designed for the Tennessee economy or for the modeling effort which has been undertaken; it can be adapted for use with any state econometric model and may also be adaptable at such substate levels as metropolitan areas where the date is available. The methodology is just a first step, requiring refinement, but it indicates the possibility of extending the traditional demand-oriented regional econometric forecasting model into the demographic and labor supply realm.

\section{FOOTNOTES}

1. J. W. Milliman, "Perspectives on Regional Manpower Planning," Southeastern Income Conference, Knoxville, Tennessee, September 1976, p. 13.

2. Lawrence Klein's 1977 presidential address to the
American Economic Association, entitled "The Supply Side," is an example of the renewed interest in supply issues.

3. For a detailed description of two typical regional 
econometric models and an extensive list of regional econometric models that have been developed, see: N. Glickman, Econometric Analysis of Regional Systems (New York: Academic Press, 1979); and R. Gustely Forecasting Regional Economic Activity: The Tennessee Econometric Model (TEM II) (Knoxville: Center for Business and Economic Research, College of Business Administration, the University of Tennessee, June 1978).

4. The region's labor force (LF) and the level of unemployment (UN) can be determined from the total number of employed people (TEP) and the unemployment rate (UR) in the following manner:

$$
\begin{aligned}
& \text { UN }=U R \times L F=(U R \times T E P) /(1-U R) \\
& L F=\text { TEP }+ \text { UN }
\end{aligned}
$$

where TEP and UR are determined within the regional model.

5. Labor supply in this paper is defined as the number of people who are working or willing to work in a particular occupation at a given wage rate. This measure of labor supply does not directly measure the number of hours available to the labor market for a particular occupation at a given point in time. There is likely to be a close correspondence between the two measures but the former measure does not take into account voluntary part-time employment, moonlighting, changes in the length of the work week or other factors that influence the total hours available to the labor market for a particular occupation.

6. A number of studies have documented the importance of labor availability in industrial plant locational decisions including: M. I. Logan, "Locational Decisions in Industrial Plants in Wisconsin," Land Economics, August 1970; Ronald Dorf and M. Jarvin Emerson, "Determinants of Manufacturing Plant Location for Nonmetropolitan Communities in the West North Central Region of the U.S.," Journal of Regional Science, April 1978; and William Miernyk, "Local Labor Market Effects of New Plant Location," in Essays in Regiomal Economics, edited by John Kain and John Meyer, Cambridge, Mass.: Harvard University Press, 1971 .

7. See Mary Currence, et al; Manpower Skill Production and Requirements in the Tennessee Valley Region (Knoxville: Center for Business and Economic Research, College of Business Administration, The University of Tennessee, February 1977), as an example of the skill inventory methodology.

8. See Norfleet Rives, Jr., "Population Projections and Regional Planning," Population Association of American Annual Meetings, Atlanta, April 1978; and D. Pittenger, Projecting State and Local Populations (Cambridge: Ballinger, 1976), for a more detailed review of demographic forecasting methodologies.

9. See Richard Easterlin, "Towards a Socioeconomic Theory of Fertility: A Survey of Recent Research on Economic Factors in American Fertility," in S. Behrman, et al. eds., Fertility and Family Planning: A World View (Ann Arbor: University of Michigan Press, 1969), for a review of the research on fertility.

10. See Michael Greenwood, "Research on Internal Migration in the United States: A Survey," Journal of Economic Literature, June 1975; and P. Neal Ritchey, "Explanations of Migration," Annual Review of Sociology, 1976, for comprehensive reviews of $\mathrm{mi}$ gration research.

11. See for example: Anthony Redwood and Morris Kleiner, "A Population Projection Methodology for
Regional Planning," Regional Science Perspectives February 1975; and Morris Kleiner, An Analysis of Interregional Migration for Manpower Planning (Urbana: Center for Advanced Computation, University of Illinois, August 1974).

12. See for example: David Kresge and Daniel Sevier, "Planning for a Resource-Rich Region: The Case of Alaska," American Economic Review, May 1978; and Richard Olsen, et al., Multiregion: A SimulationForecasting Model of BEA Economic Area Population and Employment (Oak Ridge: Oak Ridge National Laboratory, October 1977).

13. A review of research in labor force participation can be found in: Herbert Parnes, "Labor Force Participation and Labor Mobility," A Review of Industrial Relations Research, 1970; Jacob Mincer, "LaborForce Participation and Unemployment: A Review of Recent Evidence," in Robert Gordon and Margaret Gordon, eds., Prosperity and Unemployment (New York: J. Wiley and Sons, 1966); and William Bowen and T. Aldrich Finegan, The Economics of Labor Force Participation (Princeton: Princeton University Press, 1969).

14. U.S. Department of Labor, The Bureau of Labor Statistics, has been forecasting the labor force and labor force participation rates for age-sex cohorts for some time. The latest projection for the U.S. can be found in: Paul Flaim and Howard Fullerton, Jr., "Labor Force Projections to 1990: Three Possible Paths," Monthly Labor Review, December 1978.

15. The U.S. Department of Commerce publishes monthly labor force information in the Survey of Current Business but it is national data without any age-sex detail.

16. Bowen and Finegan provide a fine example of the use of cross-section analysis in examining the determinants of labor force participation.

17. A discussion of the reasons for using pooled crosssection analysis in examining regional labor force participation rates can be found in Richard Olsen, Labor Force Participation in East Tennessee (Oak Ridge: Oak Ridge National Laboratory, April 1972), and an application of this methodology can be found in Olsen, et al., Multiregion: A Simulation-Forecasting Model of BEA Economic Area Population and Employment (Oak Ridge: Oak Ridge National Laboratory, October 1977).

18. The Tennessee Econometric Model is a demandoriented Wharton satellite model. Its current configuration includes approximately 200 equations (150 behavioral and 50 identities). The model can be used to forecast the level of state economic activity in 10 sectors: output, employment, wages, personal income, banking, state government, local government, agriculture, retail sales and energy. A detailed description of an early version of the model can be found in Forecasting Regional Economic Activity: The Tennessee Econometric Model (TEM II) by Richard Gustely. Comparable documentation does not exist for the current expanded version.

19. The projections of the general fertility rate for the nation are the Series II projections from Table A-8 in "Projections of the Population of the United States: 1977 to 2050," U.S. Bureau of the Census, Current Population Reports, Series P-25, No. 704 (Washington, D.C. : U.S. Government Printing Office, 1977).

20. The historical and projected national survival rates are from Current Population Reports, Series P-25-Nos. 493 (December 1972, Table B-5); 601 (October 1975, Table B-1); and 704 (July 1977, Table B-1), 
U.S. Bureau of the Census (Washington, D.C.: U.S. Government Printing Office).

21. Both Greenwood and Ritchey provide evidence in support of this.

22. E. Muller, "Is Out-Migration Affected by Economic Conditions?", Southern Economic Journal, January 1973.

23. T. Courchene, "Interprovincial Migration and Economic Adjustment," Canadian Journal of Economics, 1970; and I. Lowry, Migration and Metropolitan Growth: Two Analytical Models (San Francisco: Chandler, 1966).

24. P. Nelson, "Migration, Real Income and Information," Journal of Regional Science, Spring 1959; M. Greenwood, "Lagged Response in the Decision to Migrate," Journal of Regional Science, December 1970; and R. Fabricant, "An Expectational Model of Migration," Journal of Regional Science, April 1970.

25. See for example, Julie DaVanzo, "Does Unemployment Affect Migration? Evidence from Micro Data," Review of Economics and Statistics, November 1978.

26. See for example R. Cebula and R. Vedder, "A Note on Migration, Economic Opportunity, and the Quality of Life," Journal of Regional Science, 1973.

27. See for example M. Greenwood, "An Analysis of the Determinants of Geographic Labor Mobility in the United States," Review of Economics and Statistics, May 1969.

28. Longitudinal panel studies such as the University of Michigan's Panel Study of Income Dynamics are not large enough to provide the necessary regional detail; and the Social Security's Continuous Work History Sample is not for the population, though both provide sources for gross flow data.

29. $\mathrm{RIMIG}_{1965,1970}^{\mathrm{U}}=\underline{\mathrm{INMIG}_{1985,1970}^{\mathrm{N}}}$ where POP $\mathrm{P}_{1970}^{\mathrm{H}}=$ $\mathrm{POP}^{11}{ }_{1970}$ population in 1970 for the $\mathrm{ij}^{\text {th }}$ age-sex cohort. POP ${ }^{10}$ 1970 is used because only the decenial census provides the age-sex detail needed to calculate the desired migration rates.

30. The lagged migration rates for the 1965-1970 observation are from the 1960 census and are for the period 1955-1960. The lagged migration rates for the 1955-1960 observation are for the 1935-1940 period because the 1950 census measured change of residence for a one period rather than a five year period.

31. The 12 southeastern states are Alabama, Arkansas, Florida, Georgia, Kentucky, Louisiana, Mississippi, North Carolina, South Carolina, Tennessee, Virginia and West Virginia.

32. A detailed description of the estimated migration equations can be found in Neil Alper, "A Methodology for Integrating a Labor Supply Model Into a Regional Economettic Forecasting Model," Working Paper No. 61, College of Business Administration, The University of Tennessee, December 1978

33. This averaging procedure was used by Olsen, et al; in Multiregion: A Simulation-Forecasting Model of BEA Economics Area Population and Employment.

34. Over the next few years the March Current Population Survey (CPS) is likely to become a very important source of age and sex specific labor force participation rates at the state and possibly local level as the size of the CPS sample increases.

35. A detailed description of the estimated labor force participation rate equations can be found in Neil Alper, "A Methodology for Integrating a Labor Supply Model Into a Regional Econometric Forecasting Model," 'Working Paper No. 61, College of Business Administration, The University of Tennessee, December 1978 .

36. The 15 to 19 year-old population cohort is adjusted using a fixed ratio to obtain the 16 to 19 year-old cohort for the labor force.

37. The occupational structure of the labor force has changed since 1970 and is very likely to change over the forecast period, but without any additional detailed information at the state level it is difficult to adjust the coefficients. The more recent sources of occupational information are either from surveys based on samples that are too small to obtain the necessary detail (Survey of Income and Education and the Current Population Survey) or from surveys that are designed for other purposes and cannot easily be modified for the needs of the model (Occupational Employment Survey). A reasonable method for updating the occupational distribution of the labor force and incorporating that information into the methodology described in this paper is certainly desirable.

38. See Table 174, "Occupation of Employed Persons by Age, Race, and Sex: 1970;" and Table 56, "Weeks Worked, Class of Worker, Last Occupation of the Experienced Unemployed and Labor Mobility, by Race, for Urban and Rural Residence: 1970," in U.S. Bureau of the Census, Census of Population: 1970, Vol. 1 "Characteristics of the Population," Part 44, Tennessee (Washington, D.C.: U.S. Government Printing Office, 1973)

39. Forecasts with greater occupational detail can be found in Goolsby, et al., An Economic Report to the Government of the State of Tennessee, Nashville: Tennessee State Planning Office, February 1979.

40. A simple model that forecasts occupational demand has been developed by the author. The forecasts are obtained by adjusting the industrial employment forecasts from the Tennessee Econometric Mode which are measured in terms of jobs, for multiple job holders and self-employed, producing industrial employment of people. These "people"adjusted employment forecasts are distributed across occupations by a Tennessee industryoccupation matrix derived from a special tabulation of the 1970 Census of Population to produce forecasts of employment demand for people. 